\title{
Risk management in the aeronautical industry: results of an application of two methods
}

\author{
H. Fukayama ${ }^{1}$, E. Fernandes ${ }^{2} \&$ N. F. F. Ebecken ${ }^{1}$ \\ ${ }^{I}$ Department of Civil Engineering, Federal University of Rio de Janeiro, \\ Brazil \\ ${ }^{2}$ Department of Production Engineering, \\ Federal University of Rio de Janeiro, Brazil
}

\begin{abstract}
This article presents the results of two risk management methods, applied in the aeronautical industry, during the development of an aircraft for the executive market. The first method is the risk management in accordance with the best practices of Project Management International (PMI), and the second is a proposal of risk management based on Multicriteria Fuzzy Analysis (MFA). The PMI method of risk management is already widely used by the market. Its terminology is quite similar to other international standards of risk management. The MFA risk management method is a new proposal that requires specialist opinions, through a questionnaire, to identify internal and external project risks, measuring their level of threat to the project success. The structure of the questionnaire follows Risk Breakdown Structure (RBS) methodology of the PMI. This new approach generates indicators at three levels: operational, tactical and strategic, which facilitates the monitoring and the management of risks. Despite its complex mathematical base, the MFA method is easier to implement. Both methods reach a similar degree of risk indicators for the project; however, the MFA can be used in an earlier phase of the project, which can avoid some possible earlier risk entanglements. Due to the particularities of each method, both show important contributions to the project risk management. Therefore, complex projects should use both methods to achieve adequate risk management. Keywords: risk management, engineering Project Management, Multicriteria Fuzzy Analysis, PMI, PMBok.
\end{abstract}




\section{Introduction}

According to Raz and Hillson [1], the origins of operational risk management can be traced to the discipline of safety engineering, which is mainly concerned with the physical harm that may occur as a result of improper equipment or operator performance. However, modern risk management has evolved substantially from there, due to a number of factors, including: 1) The shift away from dangerous physical work and towards knowledge-intensive work; 2) An expanded view of the organization in the context of its various stakeholders; 3) The growing importance of projects as the framework for planning and executing work in organizations; 4) The central role of technology, and its inherent uncertainty; 5) Ever-increasing competitive pressures to shorten lead times, causing organizations to start planning and executing their activities with incomplete information; 6) Increasing turbulence in the business environment; 7) The rapid increase in the degree of complexity embodied in business and projects; 8) The continuing trend towards globalization, and the resulting emphasis on virtual business and teams; and 9) The increasing burden of regulation with which businesses must comply.

Table 1: $\quad$ The standards of Project Management reviewed.

\begin{tabular}{|c|c|c|}
\hline Title & Author & Year \\
\hline $\begin{array}{l}\text { 1. IEEE Standard 1540-2001: Standard for Software Life Cycle } \\
\text { Processes - Risk Management }\end{array}$ & $\begin{array}{l}\text { Institute of Electrical and Electronic } \\
\text { Engineers, USA }\end{array}$ & 2001 \\
\hline $\begin{array}{l}\text { 2. CEI/IEC 62198:2001: International Standard, Project Risk } \\
\text { Management: Application Guidelines, 1st edition, 2001-04 }\end{array}$ & $\begin{array}{l}\text { International Electrotechnical Commission, } \\
\text { Switzerland }\end{array}$ & 2001 \\
\hline $\begin{array}{l}\text { 3. JIS Q2001:2001(E): Guidelines for Development and Implementation } \\
\text { of Risk Management System }\end{array}$ & Japanese Standards Association & 2001 \\
\hline 4. AS/NZS 4360:2004: Risk Management & $\begin{array}{l}\text { Standards Australia/ Standards New } \\
\text { Zealand }\end{array}$ & 2004 \\
\hline $\begin{array}{l}\text { 5. BS 6079-3:2000: Project Management-Part 3: Guide to the } \\
\text { Management of Business-related Project Risk }\end{array}$ & British Standards Institution (BSI) & 2000 \\
\hline $\begin{array}{l}\text { 6. CAN/CSA-Q850-97: Risk Management: Guideline Association for } \\
\text { Decision-Makers }\end{array}$ & Canadian Standards Association (CSA) & 1997 \\
\hline \multicolumn{3}{|l|}{ Professional standards } \\
\hline Title & Author & Year \\
\hline 7. Risk Management Standard & $\begin{array}{l}\text { Institute of Risk Management (IRM)/ } \\
\text { National Forum for Risk Management in the } \\
\text { Public Sector (ALARM)/ Association of } \\
\text { Insurance and Risk Managers (AIRMIC), } \\
\text { UK }\end{array}$ & 2002 \\
\hline 8. Project Risk Analysis \& Management (PRAM) Guide, 2nd edition & $\begin{array}{l}\text { Association for Project Management } \\
\text { (PRAM), UK. }\end{array}$ & 2004 \\
\hline $\begin{array}{l}\text { 9. Guide to the Project Project Management Body of Knowledge } \\
\text { (PMBoK@): Chapter 11, Project Risk Management, 3rd edition }\end{array}$ & Project Management Institute, USA & 2004 \\
\hline
\end{tabular}

Raz and Hillson [1] described in Table 1 nine standards that were selected from a comprehensive survey, carried out with the help of the librarian of the Standards Institute of Israel. The nine standards selected consist of six national or international standards that were developed or adopted by standardisation bodies, and three standards that were developed by professional organizations interested in risk management. All of them were recently published, the earliest publication date being 1997. In agreement with Raz and Hillson [1], we observed nine main methods of risk management and their respective authors or institutions. In the present article, we will discuss only the ninth item (risk management according to PMI), because this method was chosen by the 
aeronautical industry (in this case study) to be applied during the development of the aircraft analyzed in this work, which will demonstrate firstly, concisely, the main processes of the PMI method. Then, the proposed method of risk management will be discussed based on the Multicriteria Fuzzy Analysis. Finally, the obtained final results of each method will be demonstrated and compared.

\section{PMI risk management}

In agreement with PMI [2], project risk management includes processes that treat the accomplishment of identification, analysis, planning, monitoring and controls and planning of risk management in a project; most of these processes are continually updated during the project development. The objectives of risk management are: to increase the probability and the impact of the positive events and to reduce the probability and the impact of the adverse events on the project. Tables 2 and 3 show the models of Tables and Matrices used by the aeronautical industry study in the qualitative analyses.

Table 2: $\quad$ Definition of scale of impact.

\begin{tabular}{|c|c|c|c|c|c|}
\hline \multirow{3}{*}{ Level } & \multirow{3}{*}{$\begin{array}{l}\text { Qualitative } \\
\text { Impact }\end{array}$} & & \multicolumn{3}{|l|}{ Impact Gravity / Scale of Values } \\
\hline & & \multirow{2}{*}{$\begin{array}{c}\text { Technical impacts / } \\
\text { Quality }\end{array}$} & \multirow{2}{*}{ Period } & \multicolumn{2}{|c|}{ Cost } \\
\hline & & & & NREC & REC \\
\hline 1 & Low & $\begin{array}{c}\text { Moderate changes but } \\
\text { maintaining the same } \\
\text { approach. }\end{array}$ & $\begin{array}{l}\text { Additional activities will be } \\
\text { necessary, but in general the } \\
\text { schedule can be maintained. }\end{array}$ & $\begin{array}{c}\text { Below } \\
\text { US } \$ 50 \text { mil. }\end{array}$ & $\begin{array}{c}\text { Below } \\
\text { US } \$ 1000 .\end{array}$ \\
\hline 2 & Medium & $\begin{array}{l}\text { Not agreement of requirements } \\
\text { / functionalities of little } \\
\text { importance. Alternative exists. }\end{array}$ & $\begin{array}{l}\text { Delay in important Milestones } \\
\text { without impact the critical } \\
\text { way. }\end{array}$ & $\begin{array}{c}\text { Between } \\
\text { US\$ } 50 \text { mil and } \\
\text { US } \$ 100 \text { mil. }\end{array}$ & $\begin{array}{l}\text { Between } \\
\text { US\$ } 1000 \text { and } \\
\text { US } \$ 10.000 .\end{array}$ \\
\hline 3 & High & $\begin{array}{l}\text { Not agreement of requirements / } \\
\text { important functionalities. } \\
\text { Alternative exists. }\end{array}$ & Delay of the critical way. & $\begin{array}{c}\text { Between } \\
\text { US\$ } 100 \mathrm{mil} \\
\text { and US\$ } 2 \mathrm{mi} .\end{array}$ & $\begin{array}{c}\text { Between } \\
\text { US } \$ 10.000 \text { and } \\
\text { US } \$ 100.000 .\end{array}$ \\
\hline 4 & Catastrophic & $\begin{array}{l}\text { Without qualification / } \\
\text { product certification }\end{array}$ & $\begin{array}{l}\text { Impossible to accomplish with } \\
\text { the period of Program delivery } \\
\text { (Major Milestone Program) }\end{array}$ & $\begin{array}{r}\text { Above } \\
\text { US } \$ 2 \mathrm{mi} .\end{array}$ & $\begin{array}{c}\text { Above } \\
\text { US } \$ 100.000 .\end{array}$ \\
\hline
\end{tabular}

Table 3: Definition of probability scale and Matrices of probability and impact.

\begin{tabular}{|c|c|c|}
\hline \multirow{2}{*}{ Level } & \multicolumn{2}{c|}{ Probability } \\
\cline { 2 - 3 } & Meaning of the Level & Associated Value \\
\hline 1 & Low (hardly it will occur) & $\sim 05 \%$ \\
\hline 2 & Medium Low (it can occur) & $\sim 20 \%$ \\
\hline 3 & Medium High (great possibilities) & $\sim 50 \%$ \\
\hline 4 & High (probably it will occur) & $\sim 80 \%$ \\
\hline
\end{tabular}

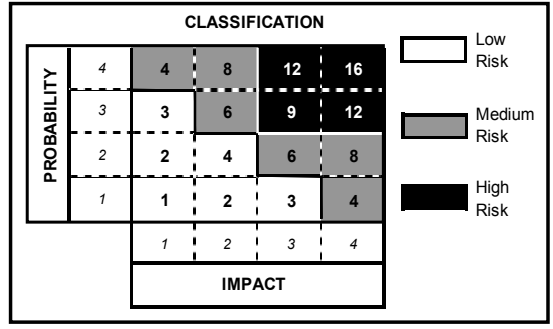

The processes of risk management include: 1) Planning of risk managementthe decision of how to approach, to draft and to execute the activities of risks management of a project; 2) Identification of risks - determination of the risks that can affect the project and documentation of their characteristics; 3) Qualitative analysis of risks - prioritization of the risks for analysis or 
subsequent additional action through the evaluation and combination of their occurrence probability and impact; 4) Quantitative analysis of risks - numeric analysis of the effect of the identified risks on the general objectives of the project; 5) Planning of answers to risks - development of options and actions to increase the opportunities and to reduce the threats to the objectives of the project; and 6) Monitoring and control of risks - attendance of the identified risks, monitoring of the residual risks, identification of new risks, execution of plans of answers to risks and evaluation of their effectiveness during the whole life cycle of the project.

\section{Risk management based on Multicriteria Fuzzy Analysis (MFA)}

The theory of fuzzy sets was introduced by Zadeh [3] as a generic approach to express the different types of uncertainty inherent in human systems. According to Zadeh [3], our ability to make precise and significant statements about systems behaviour declines as they become more complex. He proposed the use of fuzzy sets and approximation methods to model such systems. Kangari and Riggs [4] noted that most of the risk factors in projects are not always possible to transform into numerical data, in this case they suggest the linguistic approach. Ayyub et al [5] approach risk management based on fuzzy logic for the development of a four-stroke diesel ship engine. Due to analyses in the preliminary phases, projects are based on subjective information and opinions from specialists, one of the conclusions of this study was the confirmation of fuzzy methodology as an appropriate technique for risk management. Ayyub et al [5] also define five risk categories: Cost and Equipment damage, Operability, Maintainability, Personnel Death/Injury and Environmental Impact. Moreover, they also concluded that the shape of a trapezoidal input could be used to model the uncertain and imprecise information. Finally, the shape of a triangular input or a crisp value can also be used if the specialist supplies more consistent information about a specific scenario of failure. Antonsson and Otto [6] developed a method based on fuzzy logic to manage the uncertainties in engineering projects. This method, called MoI (Method of Imprecision), is applied in the preliminary phases of project developments, where the "imprecision" and the uncertainty are higher. In 2001 several articles were published in the International Journal of Project Management about risks in projects. Two of them approach the use of fuzzy logic in the evaluation of project risks (Pender [7] and Kuchta [8]) and two focused on great engineering projects (Miller and Lessard [9] and Floricel and Miller [10]). From this literature, it can be observed that the researches on risks in several types of engineering projects show the need for the development of a specific approach. In the search got robust tools for risk management in complex projects, this work explores the use of MFA for the evaluation of risks. The proposed methodology applies a questionnaire to identify the risks that can affect the engineering project and their threat level to the project success. The questionnaire structure follows the RBS (Risk Breakdown Structure) methodology of PMI [2], where the 
greatest benefit of this approach is to facilitate the identification of the risks among a lot of sources of which the risk of the project can appear. The choice of this structure, as well as the formulated subjects (primary indicators) are in agreement with several other questionnaires and/or methodologies used for the identification of risks in projects. The analytical methodology developed here has three fuzzy levels of risk indicators, as shown in the Figure 1.

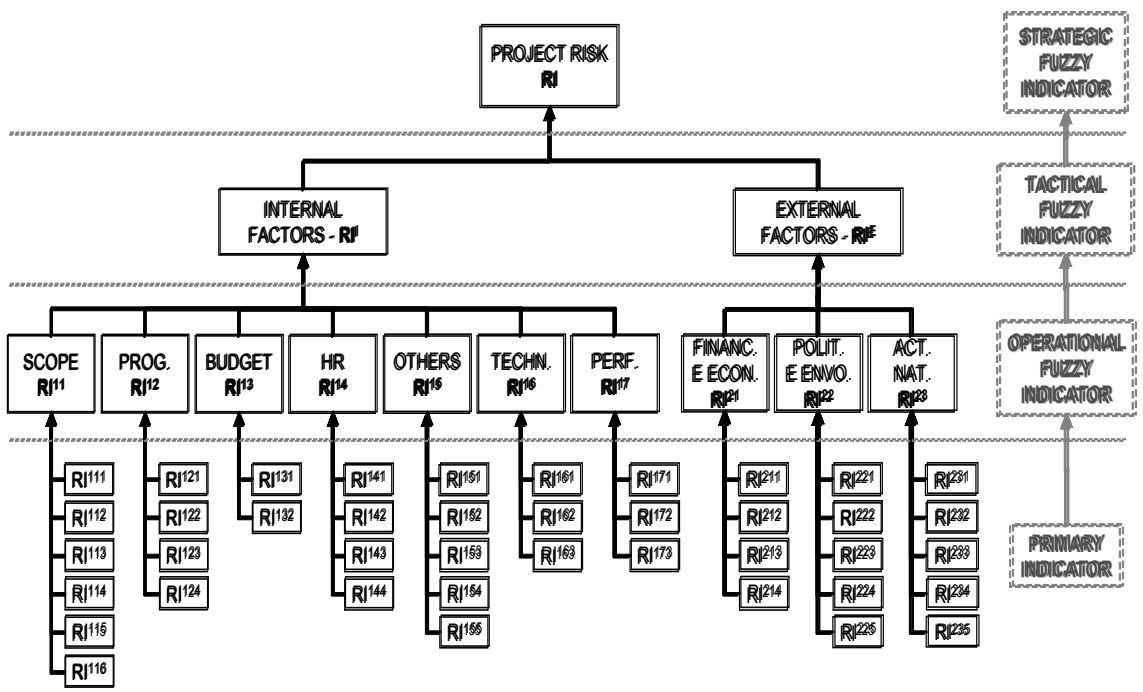

Figure 1: Questionnaire structure by RBS (Risk Breakdown Structure) and fuzzy analysis methodology.

The primary indicators are those obtained through the questions answered by the specialists $\left(\mathrm{RI}_{111}\right.$ to $\left.\mathrm{RI}_{235}\right)$. From the primary indicators, the first analysis level can develop the fuzzy risk indicators of the operational level $\left(\mathrm{RI}_{11}\right.$ to $\left.\mathrm{RI}_{23}\right)$. The operational fuzzy indicators are thus aggregated at the tactical level, generating the fuzzy internal and external indicators $\left(\mathrm{RI}^{\mathrm{I}}\right.$ and $\left.\mathrm{RI}^{\mathrm{E}}\right)$. Eventually, these two indicators at the tactical level are aggregated into one fuzzy indicator at the strategic level (RI). This thus constitutes a coherent system of cause and effect, which makes it possible to monitor the evolution of risk parameters at operational, tactical and strategic levels. This methodology, in addition to presenting a clear and transparent vision of how managers perceive project risks, also presents a simulator that allows managers to evaluate the impact of improvements in certain indicators in the overall context of risk analysis, this in three levels of management: operational, tactical and strategic.

In Table 4, the characteristics are grouped in typical categories of engineering projects risk. The risks are classified on a scale from 1 to 9 , metrically this is associated with the notion of High (9), Medium (5) and Low (1), being indicated as an evaluation pattern for each risk type. The questionnaire will identify the risk factors in the project. Once the final questionnaire is filled out by the specialists, an analysis is performed to obtain the lower, medium and upper 
bounds for the risk items and for their weights. The evaluation to obtain risk indicators, which can be analyzed in several levels of decision making (Operational, Tactical and Strategic), will be accomplished through the MFA.

Table 4: $\quad$ Primary and fuzzy indicators.

\begin{tabular}{|c|c|}
\hline RI $^{\mathbf{I}}$ & INTERNAL FACTORS \\
\hline $\mathrm{RI}^{11}$ & SCOPE \\
\hline $\mathrm{RI}^{111}$ & Scope of the project \\
\hline $\mathrm{RI}^{112}$ & Business requirements \\
\hline $\mathrm{RI}^{113}$ & Readiness of the systems \\
\hline $\mathrm{RI}^{114}$ & Quality of the data \\
\hline $\mathrm{RI}^{115}$ & Implementation \\
\hline $\mathrm{RI}^{116}$ & Standardized result \\
\hline $\mathrm{RI}^{12}$ & PROGRAMMING \\
\hline $\mathrm{RI}^{121}$ & Dates \\
\hline $\mathrm{RI}^{122}$ & Estimate of time \\
\hline $\mathrm{RI}^{123}$ & Similar programming \\
\hline $\mathrm{RI}^{124}$ & Dependence \\
\hline $\mathrm{RI}^{13}$ & BUDGET \\
\hline $\mathrm{RI}^{131}$ & Elaboration \\
\hline $\mathrm{RI}^{132}$ & Financing \\
\hline $\mathrm{RI}^{14}$ & $\mathrm{RH}$ \\
\hline $\mathrm{RI}^{141}$ & The manager's experience \\
\hline $\mathrm{RI}^{142}$ & Experience of the team \\
\hline $\mathrm{RI}^{143}$ & Co-location \\
\hline $\mathrm{RI}^{144}$ & Backer of the project \\
\hline $\mathrm{RI}^{15}$ & OTHER \\
\hline $\mathrm{RI}^{151}$ & Requirements of the work \\
\hline $\mathrm{RI}^{152}$ & Impacts of the project \\
\hline $\mathrm{RI}^{153}$ & Affected departments \\
\hline $\mathrm{RI}^{154}$ & Participation will \\
\hline $\mathrm{RI}^{155}$ & Labor subjects \\
\hline & \\
\hline
\end{tabular}

\begin{tabular}{|c|c|}
\hline $\mathrm{RI}^{16}$ & TECHNOLOGY \\
\hline $\mathrm{RI}^{161}$ & Technological maturity \\
\hline $\mathrm{RI}^{162}$ & Technical requirements \\
\hline $\mathrm{RI}^{163}$ & Technological knowledge \\
\hline $\mathrm{RI}^{17}$ & PERFORMANCE \\
\hline $\mathrm{RI}^{171}$ & Performance objectives \\
\hline $\mathrm{RI}^{172}$ & Implementation easiness \\
\hline $\mathrm{RI}^{173}$ & Sub-contracts \\
\hline $\mathbf{R I}^{\mathbf{E}}$ & EXTERNAL FACTORS \\
\hline $\mathrm{RI}^{21}$ & FINANCIAL $\backslash$ ECONOMICAL \\
\hline $\mathrm{RI}^{211}$ & Inflation \\
\hline $\mathrm{RI}^{212}$ & Tax of exchange \\
\hline $\mathrm{RI}^{213}$ & Price of services \\
\hline $\mathrm{RI}^{214}$ & Stability Sub-contracts \\
\hline $\mathrm{RI}^{22}$ & POLITICAL \ENVIRONM. \\
\hline $\mathrm{RI}^{221}$ & Laws \\
\hline $\mathrm{RI}^{222}$ & Government \\
\hline $\mathrm{RI}^{223}$ & The community's position \\
\hline $\mathrm{RI}^{224}$ & Ambient \\
\hline $\mathrm{RI}^{225}$ & The community's interference \\
\hline $\mathrm{RI}^{23}$ & ACTIONS OF THE NATURE \\
\hline $\mathrm{RI}^{231}$ & Conditions of the time \\
\hline $\mathrm{RI}^{232}$ & Inundations \\
\hline $\mathrm{RI}^{233}$ & Windstorms \\
\hline $\mathrm{RI}^{234}$ & Fires \\
\hline $\mathrm{RI}^{235}$ & Earthquake \\
\hline
\end{tabular}

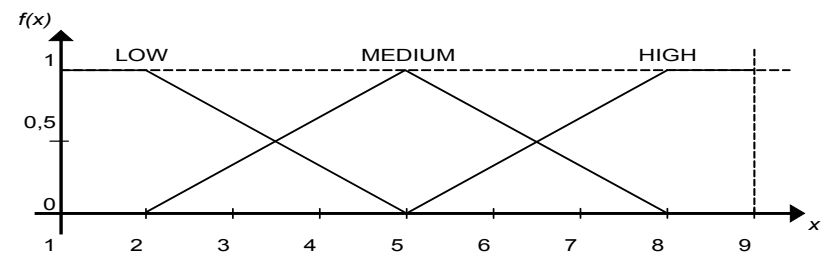

Figure 2: Input and output - linguistic term.

The main element that guides decision making in fuzzy modelling is a rule of the form: if A (observed event - input) then B (resulting event - output). The observed events and resulting events are expressed in linguistic terms (Figure 2).

These linguistic terms seek to represent the complexity of the measurement. The fuzzy set of inputs A and outputs B can be represented by equations 1 and 2, respectively.

$$
\begin{aligned}
& \mathrm{A}=\{\mathrm{x}, \mathrm{f}(\mathrm{x}), \mathrm{x} \in \mathrm{R} \text { and } \mathrm{f}(\mathrm{x}) \in \mathrm{R} \mid 1 \leq \mathrm{x} \leq 9 \text { and } 0 \leq \mathrm{f}(\mathrm{x}) \leq 1\} \\
& \mathrm{B}=\{\mathrm{y}, \mathrm{f}(\mathrm{y}), \mathrm{y} \in \mathrm{R} \text { and } \mathrm{f}(\mathrm{y}) \in \mathrm{R} \mid 0 \leq \mathrm{y} \leq 1 \text { and } 0 \leq \mathrm{f}(\mathrm{y}) \leq 1\}
\end{aligned}
$$

$$
f\left(X_{B}\right)= \begin{cases}1, & \text { if } X<2 \\ \frac{5-X}{3}, & \text { if } 2 \leq X \leq 5 \\ 0, & \text { if } X>5\end{cases}
$$




$$
\begin{gathered}
f\left(X_{M}\right)= \begin{cases}0, & \text { if } X<2 \\
\frac{X-2}{3}, & \text { if } 2 \leq X<5 \\
\frac{8-X}{3}, & \text { if } 5 \leq X \leq 8 \\
0, & \text { if } X>8\end{cases} \\
f\left(X_{A}\right)= \begin{cases}0, & \text { if } X<5 \\
\frac{X-5}{3}, & \text { if } 5 \leq X \leq 8 \\
1, & \text { if } X>8\end{cases}
\end{gathered}
$$

The rules of the decision making process (if $\mathrm{x}$ then $\mathrm{y}$ ) are subject to weightings (W). This weighting reflects the relative influence of the rule in the result, because the result is composed of an operation of the union of the rules according to a certain criterion. Given these elements, the tools of the set theory are used for the process called fuzzification and through a deterministic mathematical method called defuzzification the numeric result of the analysis is obtained. The result of this process supplies an index resulting from the application of the inputs in the unit of observation being monitored, according to the fuzzy model defined for the analysis [11]. Through this index, built by several inputs and in agreement with specialist opinions, the level of project risk is determined for each category of risk indicators.

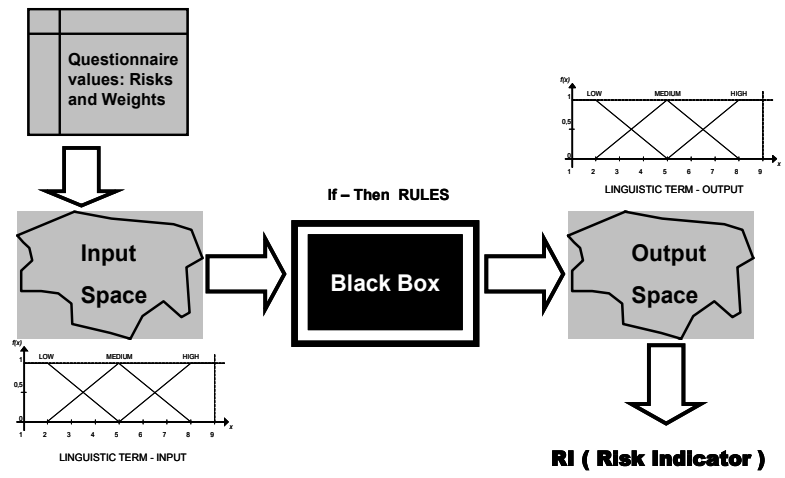

Figure 3: $\quad$ Fuzzification and desfuzzification analysis.

\section{Results}

To evaluate the proposed methodology, the aeronautical industry was chosen due to some of its characteristics, which are important for this case study, such as high complexity and uncertainty. The project used in the analyses was the development of an aircraft for the executive market (ultra-large category) with a value of about 40 million dollars. The foreseen duration of this project was esteemed initially as two years. In agreement with Dinsmore and Cavalieri [12], in the beginning of the project there are more uncertainties involved that decrease as the project advances. The impact of the risks, unlike the uncertainty, increases as time passes and the end of the project is imminent. Figure 4, 


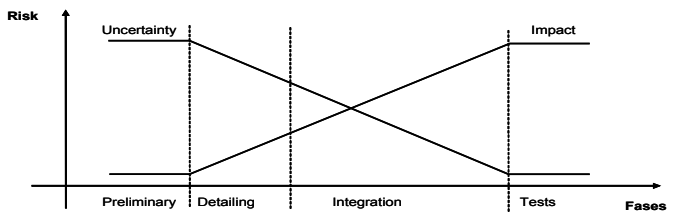

Figure 4: Uncertainty versus impact of the risk in the life cycle of the project.

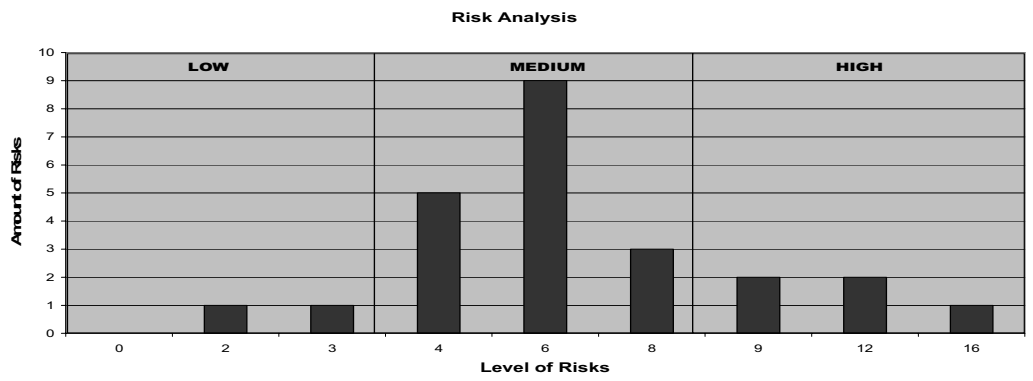

Figure 5: Risk identification - aircraft project.

extracted from Dinsmore and Cavalieri [12], shows in a generic way the evolution of the uncertainties and the impact of the risk along the project life cycle.

With the objective of acquiring a better result in the application of the proposed methodology, the Detailing Phase of the project was chosen for application of the questionnaire. This choice is due to the existence in this phase of the following items: 1) Teams already formed and with the minimum knowledge necessary of the project; 2) All of the technological areas (structures, electric, propulsion, aeronautics, etc) necessary for the development of the product already involved and 3) Uncertainties due to the final result are difficult to evaluate.

\subsection{Final results: risk management in accordance with best practices of Project Management International (PMI)}

In the process of risk identification, specialists analyze several technologies during several meetings. After identification, the risks were qualified according to the definition tables of Probability and Impacts, through a consensus among all the participants. After this qualitative analysis, 24 potential risks were selected. Their distribution (High, Medium and Low) is shown in Figure 5.

From Figure 5 we have the following percentages: $08 \%$ of Low risks, $71 \%$ of Medium risks and $21 \%$ of High risks. Demonstrated this way, a great part of the risks of the project are of MEDIUM level.

\subsection{Risk management based on Multicriteria Fuzzy Analysis (MFA)}

The questionnaire was completed by 16 specialists, among them the Project Manager responsible for the development of this product. The participant areas were: Weight Control, Interiors, Environmental Systems, Landing Gear, Ground 
and Flight Tests, Aeronautics, Propulsion, Configuration Engineering, Customer Support, RH and Planning. For the determination of the final values of risk (RI), the primary indicators were joined at the operational level, resulting later in new tactical and strategic levels indicators. For the analysis, the use of the following linguistics terms were chosen: Low (trapezoidal), Medium (triangular) and High (trapezoidal). In other studies already observed the following linguistics terms were also used: Very low, Low, Medium, High and Very High - all in the triangular form. To arrive at this choice, simulations were accomplished with the two cases, where significant differences were not obtained. This way was opted for as the simplest solution in the computational modelling vision and the specialist's understanding at the time of the research. The final result, in agreement with the three notable points of the space of the alpha-cut (Gheorghe et al $[13,14])$ approach solutions, is in Table 5.

Table 5: $\quad$ Results of the Fuzzy analysis.

\begin{tabular}{|c|c|c|c|c|}
\hline & & $\mathrm{w}_{\mathrm{UB}} \cdot \mathrm{C}_{\mathrm{UB}}$ & $\mathbf{W}_{\mathrm{ME}} \cdot \mathrm{C}_{\mathrm{ME}}$ & $\mathbf{W}_{\mathrm{LB}} \cdot \mathbf{C}_{\mathrm{LB}}$ \\
\hline $\mathbf{R I}^{\mathbf{1}}$ & INTERNAL FACTORS & 6,56 & 5,03 & 3,49 \\
\hline $\mathrm{RI}^{11}$ & SCOPE & 6,66 & 5,14 & 3,54 \\
\hline $\mathrm{RI}^{12}$ & PROGRAMMING & 8,59 & 6,12 & 4,36 \\
\hline $\mathrm{RI}^{13}$ & BUDGET & 5,75 & 4,60 & 2,58 \\
\hline $\mathrm{RI}^{14}$ & $\mathrm{RH}$ & 3,46 & 2,71 & 1,96 \\
\hline $\mathrm{RI}^{15}$ & OTHER & 6,05 & 4,61 & 2,96 \\
\hline $\mathrm{RI}^{16}$ & TECHNOLOGY & 5,71 & 3,89 & 1,15 \\
\hline $\mathrm{RI}^{17}$ & PERFORMANCE & 6,59 & 4,44 & 2,27 \\
\hline $\mathbf{R I}^{\mathrm{E}}$ & EXTERNAL FACTORS & 4,67 & 4,28 & 3,27 \\
\hline $\mathrm{RI}^{21}$ & FINANCIAL AND ECONOMICAL & 5,34 & 4,14 & 2,46 \\
\hline $\mathrm{RI}^{22}$ & POLITICAL AND ENVIRONMENTAL & 4,37 & 3,29 & 1,00 \\
\hline $\mathrm{RI}^{23}$ & ACTIONS OF THE NATURE & 3,86 & 3,41 & 1,19 \\
\hline RI & RISK INDICATOR & 5,59 & 4,68 & 4,10 \\
\hline
\end{tabular}

Through Table 5, we observed that all the limits (superior, medium and inferior) pointed to a risk of MEDIUM level for the project. In other words, if we use the equations 3,4 and 5, we will observe that the largest value will always be for the $f\left(X_{m}\right)$, for all the values of the limits above.

- $\quad$ Superior = 5,59 (0\% Low, 80,3\% Medium and 19,7\% High)

- Medium = 4,68 (10,7\% Low, 89,3\% Medium and 0\% High)

- $\quad$ Inferior $=4,10$ (30\% Low, 70\% Medium and 0\% High)

\section{Conclusion}

From the comparison of the presented methodologies, it can be verified that both final results indicate a Medium risk degree for the project. Hence, the reliability of the proposed fuzzy methodology could be attested, because it performed the same results of a sound methodology. Moreover, the method based on fuzzy analysis possesses some other advantages: 1) There is no need for extensive meetings with all the participants to obtain a consensus on the risk; 2) There is a low necessity for precise data, therefore it can be applied earlier (in the preliminary phases of the project); 3) It requires few specialists for data collecting and 4) The possibility of risk tracking, through the three managerial levels: operational, tactical and strategic. 
As a suggestion, the proposed fuzzy method and the PMI method can be used together. The first reaches results more promptly and allows for a wider set of risk factors. The PMI method started with 24 factors, obtained from the specialists' views, while the MFA method evaluated 41 factors obtained from literature. So it may help in the decision about what is more critical. Also, the fuzzy method can be applied in preliminary project phases, where there is not much precise information, nor a formed team; it will indicate where the greatest risk is (Scope, RH, Technology, Budget, etc) and, thus, efforts can be focused on risk identification through the PMI method. Moreover, sooner risk identification could reduce cost and effort for its mitigation.

\section{References}

[1] Raz, T. \& Hillson, D., A Comparative Review of Risk Management Standards. Risk Management: An International Journal, 7 (4), 53-66, 2005.

[2] Project Management Institute (US) Standards Committee. A Guide to the Project management Body of Knowledge, PMI lnc. Pennsylvania, 2004.

[3] Zadeh, L.A., Outline of a New Approach to the Analysis of Complex Systems and Decision Processes. IEEE Transactions on Systems, Man and Cybernetics 3, 28-44, 1973.

[4] Kangari, R. \& Riggs L.S., Construction Risk assessment by Linguistics. IEEE transactions on Engineering Management, 36 (2), 126-131, 1989.

[5] Ayyub, B. M., Karaszewski, Z. \& Klim, Z., Fuzzy-Based Decision Analysis for Risk Assessment of Marine Systems. AIAA Fórum, No 99-1578, 1999.

[6] Antonsson, E. K., Otto, K. N., Imprecision in Engineering Design. ASME Journal of Mechanical Design, 117(B), 1995.

[7] Pender, S., Managing Incomplete Knowledge: Why Risk management is not sufficient. International Journal of Project Management, 19, 79-87, 2001.

[8] Kuchta, O., Use of Fuzzy Numbers in Project (Criticality) Assessment. International Journal of Project Management, 19, 305-310, 2001.

[9] Miller, R. \& Lessard, O., Understanding and Managing Risks in Large Engineering Projects. International Journal of Project Management, 19, 437-443, 2001.

[10] Floricel, S. \& Miller, R., Strategizing for Anticipated Risks and turbulence in Large-scale Engineering projects. International Journal of Project Management, 19,445-455, 2001.

[11] The MathWorks. Fuzzy Logic Toolbox User's Guide. The MathWorks, Inc.: Natick, 2002.

[12] Dinsmore, P. C., \& Cavalieri, A. Como se tornar um profissional em gerenciamento de projetos. Qualitymark: Rio de Janeiro, 2003.

[13] Gheorghe, R., Bufardi, A., Xirouchakis, P., Construction of a twoparameters fuzzy outranking relation from fuzzy evaluation. Fuzzy Sets and Systems 143, 391-412, 2004.

[14] Gheorghe, R., Bufardi, A. \& Xirouchakis, P., Construction of global fuzzy preference structures from two-parameter single-criterion fuzzy outranking relations. Fuzzy Sets and Systems 153, 303-330, 2005. 